\title{
Globalização, Estado, políticas públicas e exclusão digital: interrelacionando conceitos
}

\author{
Globalization, State, public policies, and digital exclusion: interrelating \\ concepts
}

\author{
Nelceia Margareth da Silva Figueiredo Chermont \\ Secretaria de Estado da Educação do Amapá \\ Lia Machado Fiuza Fialho \\ Universidade Estadual do Ceará
}

\begin{abstract}
Resumo: O texto trata acerca da interface entre conceitos importantes, tais como globalização, Estado, políticas públicas e Tecnologias Digitais de Informação e Comunicação. O mote foi elaborar um ensaio como objetivo de discutir a interface entre a globalização e as TDIC, considerando as políticas públicas para sua universalização numa sociedade eminentemente capitalista. Fundamentado principalmente nos estudos de Bauman (2001; 2008), Souza (2003), Kenski (2007), Alves (2011) e Santana, Oliveira e Meira (2013). Discute-se que as TDIC fomentaram a globalização e a ampliação do sistema capitalista. Todavia, não reverberou em maior igualdade e justiça social, na contramão, o Estado não consegue assegurar a inclusão digital e, na lógica da acumulação do capital, parte considerável da população brasileira permanece sem conhecimento para fazer uso dos artefatos digitais e recursos para a sua aquisição ou acesso. Esse quadro de exclusão foi asseverado em tempos de pandemia causada pela Covid-19.
\end{abstract}

Palavras-chave: Estado democrático; Desigualdade social; Inclusão digital.

\begin{abstract}
The text deals with the interface between important concepts, such as globalization, State, public policies and Digital Technologies of Information and Communication. The motto was to elaborate an essay with the objective of discussing the interface between globalization and TDIC, considering public policies for their universalization in an eminently capitalist society. Based mainly on studies by Bauman (2001, 2008), Souza (2003), Kenski (2007), Alves (2011) and Santana, Oliveira and Meira (2013), it is argued that TDIC fostered globalization and the expansion of the system. capitalist. However, it did not reverberate in greater equality and social justice, on the contrary, the State cannot ensure digital inclusion, and, in the logic of capital accumulation, a considerable part of the Brazilian population remains without knowledge to use digital artifacts and resources for their acquisition or access. This exclusion picture was asserted in times of pandemic caused by COVID-19.
\end{abstract}

Keywords: Democratic State; Social inequality; Digital inclusion. 


\section{INTRODUÇÃO}

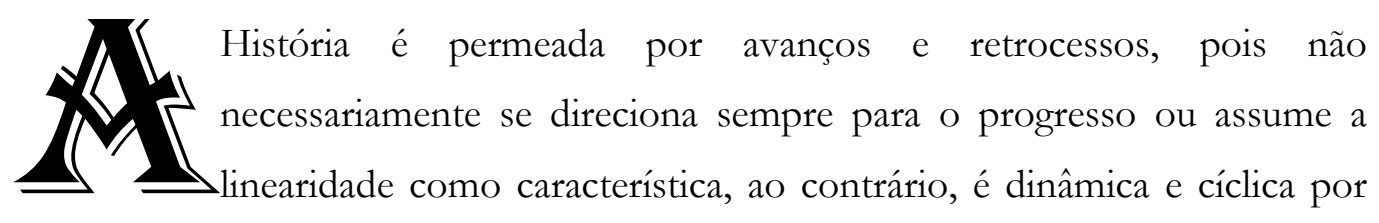
ser constituída pelas ações e interações da humanidade no espaço geográfico (ARANHA, 1996; CAMBI, 1999; GADOTTI, 2006; BITTAR, 2009). Todavia, o artigo em tela não possui a pretensão de dar a ver todas as nuances que perpassam a vida dos homens, pois trata especificamente da interface entre a globalização e as políticas públicas de fomento à universalização das Tecnologias Digitais de Informação e Comunicação (TDIC). Inclusive, lança lume à exclusão digital que ainda acomete parte significativa da população brasileira.

Questiona-se como as políticas públicas foram sendo desenvolvidas para a universalização das TDIC ante uma sociedade globalizada, que cada vez mais exige o uso de artefatos tecnológicos. A partir dessa inquietação, elabora-se um ensaio como objetivo de discutir a interface entre a globalização e as TDIC, considerando as políticas públicas para a sua universalização numa sociedade eminentemente capitalista. A relevância de se discutir criticamente essa temática consiste no fato de que é necessário refletir acerca das desigualdades que assolam a população brasileira no que concerne ao acesso às TDIC, pois elas asseveram o fosso das dissimetrias que caracterizam a concentração de renda no Brasil.

A discussão inicia-se pela globalização, ao explicitar essa categoria temática considerando a forma de produção atual, o capitalismo. Em seguida explora-se a relação do Estado capitalista com as TDIC. Afinal, são termos interdependentes, indissociáveis, portanto, estão correlacionados. Para finalizar, aborda-se as políticas públicas como forma de garantia de acesso da sociedade aos direitos sociais, mais especificamente, como o Estado manifesta-se para assegurar à sociedade o acesso às TDIC por intermédio das políticas públicas e a exclusão digital asseverada pela ingerência do poder público.

\section{A GLOBALIZAÇÃO E A SOCIEDADE CAPITALISTA}

Na obra Modernidade Líquida (2001), Zygmunt Bauman', um dos mais importantes sociólogos da atualidade, trata das consequências dessas evoluções à vida da humanidade. Ele afirma que na transformação do mundo sólido ao líquido ocorre a

\footnotetext{
${ }^{1}$ Professor emérito das universidades de Leeds (Inglaterra) e Varsóvia (Polônia). Bauman definiu como modernidade líquida um período que se iniciou após a Segunda Guerra Mundial e ficou mais perceptível a partir da década de 1960. Esse sociólogo chamou de modernidade sólida o período anterior. Disponível em: https://mundoeducacao.uol.com.br/sociologia/modernidade-liquida.htm. Acesso em: 09 abr. 2021.
} 
liquefação das formas sociais, ou seja, alguns aspectos como o trabalho, a família, as amizades produzem no ser humano, alguns males como "angústia, ansiedade, a instabilidade econômica mundial.(s.p.)" Nesse cenário, o surgimento de novas tecnologias e da globalização, contribuíram para a perda da ideia de controle sobre os processos do mundo, trazendo incertezas quanto à capacidade dos seres humanos de se adequarem aos novos padrões sociais, que mudam constantemente (BAUMAN, 2001).

Compreende-se que, com o processo de globalização, o mundo foi-se constituindo de uma aldeia global, todavia, ainda que as distâncias e as fronteiras tenham sido encurtadas, as desigualdades mundiais não foram minimizadas, ao contrário, a acumulação do capital relega boa parte da população à situação de miséria. A globalização, dessa maneira, é "a integração mais próxima de países e povos do mundo [...] causada pela enorme redução de custos [...] e pela eliminação de barreiras artificiais para os fluxos de mercadorias, serviços, capital, conhecimento [...] através das fronteiras internacionais" (STIGLITZ, 2008. p. 191), com efeito, ainda não se conseguiu constituir uma identidade planetária (MORIN; CIURANA; MOTTA, 2003).

Sabe-se, contudo, que os países que investem em ciência, e tornam-se proprietários das inteligências artificiais, acabam por ditar as regras de mercado. François Chesnais, no artigo científico intitulado "A globalização e o curso do capitalismo de fimde-século" afirma que,

[...] São raros os termos econômicos tão impregnados de ideologia quanto a palavra globalização. Num grau ainda mais elevado do que para a expressão progresso técnico, estaríamos frente a um processo em relação ao qual a sociedade mundial contemporânea, em seus diversos componentes - os países e, dentre esses, as classes sociais -, não teria opção a não ser se adaptar. Trata-se de uma palavra-chave que constitui hoje em dia verdadeiro slogan das organizações econômicas internacionais. Dever-se-ia, portanto, banir toda e qualquer tentativa de orientar ou de domar o processo. No alvorecer do século XXI, a globalização constituiria a própria expressão da modernidade, notadamente por ser o resultado das forças do mercado, finalmente liberadas, pelo menos parcialmente, das correntes nocivas com que o Estado lhes manietou durante meio século (CHESNAIS, 1995, p. 02, grifos nossos).

Entende-se que a globalização está associada a uma nova ordem mundial, que não gerou o progresso técnico de forma igualitária. Dessa maneira, na modernidade, os Estados tensionam as forças do mercado com o objetivo de ampliar seu capital e não da promoção de maior justiça social. Zygmunt Bauman na obra "Sociedade individualizada: vidas contadas e histórias vividas" (2008, p. 48), afirma que o "o termo globalização se refere à natureza desordenada dos processos que ocorrem acima do território 
principalmente coordenado e administrado pelo mais alto nível do poder institucionalizado, isto é, Estados soberanos". Visto dessa forma, compreende-se que a globalização extinguiu as fronteiras e os limites dos espaços territoriais no que concerne ao trânsito das tecnologias, mercadorias, dentre outros (NASCIMENTO; FIALHO, 2020).

Como celeiro da globalização e dos avanços das tecnologias, importa destacar o modo de produção capitalista:

O que caracteriza o modo de produção capitalista são as relações assalariadas de produção (trabalho assalariado). As relações de produção capitalistas baseiam-se na propriedade privada dos meios de produção pela burguesia, que substituiu a propriedade feudal, e no trabalho assalariado, que substituiu o trabalho servil do feudalismo. O capitalismo é movido por lucros, portanto temos duas classes sociais: a burguesia e os trabalhadores assalariados. O capitalismo compreende quatro etapas: Pré-capitalismo: o modo de produção feudal ainda predomina, mas já se desenvolvem relações capitalistas. Capitalismo comercial: a maior parte dos lucros concentram-se nas mãos dos comerciantes, que constituem a camada hegemônica da sociedade; o trabalho assalariado torna-se mais comum. Capitalismo industrial: com a revolução industrial, o capital passa a ser investido basicamente nas indústrias, que se tornam a atividade econômica mais importante; o trabalho assalariado firma-se definitivamente. Capitalismo financeiro: os bancos e outras instituições financeiras passam a controlar as demais atividades econômicas, através de financiamentos à agricultura, à indústria, à pecuária, e ao comercio (GONÇALVES, s/d, p. 04-05).

Sabe-se que a produção capitalista inicia-se sobre a crise geral da produção feudal dos séculos "XIV e XV, esta é marcada por agudas lutas sociais das quais participam a nobreza, o campesinato, o clero, a realeza, a burguesia nascente e o artesanato urbano" (OLIVEIRA, 2003, p. 103). Essa crise foi aprofundada pela formação dos Estados Nacionais, pelas grandes navegações, pelo mercantilismo, pela ação da burguesia mercantil, pela acumulação de capitais nas mãos de comerciantes, banqueiros etc.

Octávio Ianni (1995 apud ALVES, 2011, p. 07), usando uma metáfora grega, afirma que, "o capitalismo desacorrentou Prometeu" do castigo que lhe havia imposto Zeus, por ensinar aos homens o segredo do fogo, [...]. Mas também é possível dizer que Prometeu escapou da tutela de Zeus e foi colocado sob a tutela do Capital". Ou seja, o capitalismo sobrepôs-se às formas anteriores de produção e, por intermédio do mercantilismo, dissipou-se mundo afora gerando não a inevitável globalização, mas o aprisionamento a um sistema econômico que não consegue promover a igualdade e a justiça social.

\footnotetext{
${ }^{2}$ Disponível em: https://books.google.com.br/books?id=nXLTDwAAQBAJ\&pg=s. Acesso em 10 abr. 2021.

${ }^{3} \mathrm{Na}$ mitologia grega, Prometeu era uma divindade. O Deus do fogo.
} 
Alves (2011, p. 04) explicita a ideia de como o capitalismo foi-se desenvolvendo para alcançar o seu sentido mais pleno, quebrando as amarras fronteiriças por meio da globalização:

Ao longo da história, desde o século XVI ao XX, e já prenunciando o século XXI, multiplicam-se as empresas, corporações e conglomerados, compreendendo monopólios, trustes, cartéis, multinacionais e transnacionais. São empreendimentos que estão sempre ultrapassando fronteiras geográficas e históricas, atravessando mares e oceanos, instalando-se em continentes, ilhas e arquipélagos. Assim, se é verdade que o mercantilismo, o colonialismo e o imperialismo tinham raízes no nacionalismo e ajudaram a difundir o modelo de Estado-nação pelo mundo afora, é também verdade que quebraram fronteiras de tribos, clãs, povos, nacionalidades, culturas e civilizações. Nesse sentido é que o capitalismo entra decisivamente no desenho (e redesenho) do mapa do mundo, criando nações e colônias, metrópoles e impérios, geoeconomias e geopolíticas, ocidentes e orientes (ALVES, 2011, p. 04).

Concorda-se com Alves (2011) que o capitalismo foi-se ampliando de maneira desigual, no qual há países que amargam a exploração de outros, ademais, a situação de competição entre as economias dos países nunca foi igual, o que escancarou as desigualdades. Inclusive, Alves (2011), amparado nas ideias de Marx e Weber, acrescenta:

Lendo Marx, pode-se dizer que a globalização surge com o domínio do capital em geral, do capital financeiro, do débacle do socialismo real, do domínio das empresas, conglomerados e corporações transnacionais e não apenas isso, mas do predomínio das instituições e tecnoestruturas transnacionais, da cultura global, shopping center global, que se impõe sobre as culturas regionais e nacionais. Lendo Weber, diremos isso e outras coisas, quando vemos a globalização que surge do processo de racionalização, da burocratização universal, do desencantamento do mundo (2011 p. 07).

Esse sistema econômico capitalista interfere diretamente na organização social, e, segundo Bauman (2008), gera dificuldades e entraves que não podem ser normalizados pela humanidade no processo de globalização. Sobre isso ele lecionar que: "Globalização indica uma espécie de 'naturalização' do curso que as questões mundiais estão tomando, isto é, estão ficando essencialmente fora de limites e de controle, adquirindo um caráter quase elementar, não planejado, não antecipado, espontâneo e contingente (BAUMAN, 2008, p. 97-98).

A globalização e a expansão do capitalismo apoiam-se na utilização das TDIC, e estas passam a fazer parte do cotidiano e do modo de vida citadino da humanidade, como se discute na seção seguinte. 


\section{AS TDIC E A GLOBALIZAÇÃO}

As mudanças ocasionadas pela globalização e pelo sistema capitalista são percebidas mundialmente. Todavia, boa parte das alterações nas relações comerciais, sociais e econômicas foram impulsionadas pelo avanço das TDIC. Segundo Kenski (2007, p. 19), "as tecnologias invadem as nossas vidas, ampliam a nossa memória, garantem novas possibilidades de bem-estar e fragilizam as capacidades naturais do ser humano". Para a autora, nós, "somos muito diferentes dos nossos antepassados e nos acostumamos com alguns confortos tecnológicos - água encanada, luz elétrica, fogão, sapatos, telefone - que nem podemos imaginar como seria viver sem eles" (KENSKI, 2007, p. 19).

A evolução tecnológica não se restringe apenas aos novos usos de equipamentos e produtos, afinal, as TDIC "engloba a totalidade de coisas que a engenhosidade do cérebro humano conseguiu criar em todas as épocas, suas formas de uso e de suas aplicações.” (KENSKI, 2007, p. 23). Assim sendo, foi o processo de produção industrial da informação que ampliou o uso das tecnologias da inteligência e "novos meios de comunicação como telegramas, cartas, jornais, revistas, rádio, cinema, vídeos, etc., ampliaram os acessos às notícias e informações" (p. 27). Na contemporaneidade, o que nasceu como tecnologia da inteligência, estrutura-se em outras formas materiais $\mathrm{e}$ estabelece-se como meios de comunicação de massa, suportes midiáticos populares, com ampla aceitação social. "Baseados no uso da linguagem oral, da escrita e da síntese entre som, imagem e movimento, o processo de produção e o uso desses meios compreendem tecnologias específicas de informação e comunicação, as TICs” (KENSKI, 2007, p. 27-28).

Correia e Santos (2013, p. 04) também utilizam a denominação TIC, por acreditarem que "[...] Tecnologias de Informação e Comunicação, diz respeito aos procedimentos, métodos e equipamentos usados para processar a informação e comunicála aos interessados". Todavia, importa esclarecer que nesse estudo optou-se por adotar a terminologia TDIC, por compreender que esta é mais atual e ser utilizada por estudiosos do campo como Lévi (2011), Di Felice (2013), Bersch e Schlemmer (2017), dentre outros.

\section{ESTADO E POLÍTICAS PÚBLICAS NO ÂMBITO DAS TDIC}

Assim como não é possível tratar de Globalização sem interrelacioná-la ao capitalismo, não seria coerente tratar de políticas públicas no âmbito das TDIC sem mencionar o Estado, pois que esse é o principal responsável por planejar e executar as 
ações e/ou políticas de Governo. Compreender o que é o Estado ${ }^{4}$, todavia, faz-se necessário. Para isso é preciso conhecer alguns conceitos sobre o Estado, em vários momentos históricos, e sob os olhares de importantes teóricos a partir do século XVI, com o surgimento dos Estados Nacionais.

O filósofo italiano Nicolau Maquiavel (1469-1527), ao tratar dos principados em sua obra "O Príncipe", procurou convencer o leitor para a importância dos principados hereditários, para, depois falar sobre os Estados novos. Ora, Maquiavel fala da permanência do soberano no poder, pois ele trata de um período absolutista, como se percebe no pensamento a seguir:

Para ele, a semelhança entre os Estados hereditários e os Estados novos
é que ambos nascem do uso da força, da violência. A diferença, no
entanto, é o tempo em que os fatos ocorreram. O Estado hereditário,
por ser mais antigo do que o Estado novo, leva os súditos a esquecerem
do uso da força empreendida pelo príncipe para conquistá-lo. Desse
modo, o Estado hereditário é legítimo pelo hábito dos súditos de
estarem submetidos ao poder de um monarca. Eis porque, segundo
Maquiavel, é mais fácil administrar e preservar um Estado hereditário do
que um Estado novo. '[...]. Digo, pois, que, nos Estados hereditários e
acostumados à linhagem de seus príncipes, são bem menores as
dificuldades para conservá-los do que nos novos [...].' (MAQUIAVEL,
2004, p. 05 apud WINTER, 2006, p. 123-124).

Maquiavel ressalta a importância da obediência dos súditos para manter a ordem, ainda que sejam submetidos à dominação pela força, bem como o "novo" modelo de dominar sem o uso da violência física. Já para o inglês Thomas Hobbes (1588-1679), também defensor do absolutismo, o homem troca sua liberdade voluntariamente em busca da segurança garantida pelo Estado-Leviatã. Conscientemente, ele confere ao soberano o poder pleno de legislar em seu nome e acaba por firmar um contrato de submissão, no qual a emergência do Estado dá-se por meio da outorga e do contrato, ou seja, o Estado seria o próprio soberano. Nesse caso a dominação seria acordada por uma forma contratual:

A única função do Estado é manter a paz entre os cidadãos. Cada
homem, ao querer possuir o que entende ser necessário para si mesmo,
pode entrar em conflito com outro que poderá querer a mesma coisa. Se
não houver quem regule, quem organize a convivência humana, o que
impera é a lei do mais forte, ou mais astuto. Sempre haverá alguém que
poderá colocar em risco minha sobrevivência se eu não tiver como me
proteger. O Estado surge como necessidade de construção da paz.
Abrimos mão de nossas capacidades de autoconservação, de autodefesa
e as delegamos ao Estado, constituído através de um contrato, para que
cuide de nossa segurança, para que possamos viver civilizadamente, para

${ }^{4}$ Grafado com letra maiúscula.

Cadernos GPOSSHE On-line, Fortaleza, v. 4, n. Único, 2021. 
que não vivamos em eterna guerra de todos contra todos (BREIER, 2008, p. 04).

O filosofo inglês John Locke (1632-1704), parte dessa ideia do contrato social como mediador da passagem do estado de natureza para o Estado Civil. Diferentemente das ideias de Hobbes, no estado de natureza de Locke reina a liberdade e a igualdade, "o estado de natureza é um estado de paz, boa vontade, assistência mútua e preservação" (MELLO, 1995, p.93 apud SANTANA; OLIVEIRA; MEIRA, 2013, p. 01). Pode-se dizer que a tese de Locke é de defesa de uma forma de democracia, na qual o povo seria o centro do poder. Fala-se em igualdade, em resistência, o que caracteriza a luta pelo bem comum.

\begin{abstract}
A liberdade natural é algo inerente à própria natureza humana, não é outorgada por nenhum tipo de governo. Ela é expressa na forma do direito à vida, a liberdade individual $\mathrm{e}$ o direito à propriedade. $\mathrm{O}$ estado de natureza ganha uma conotação positiva, mas este Estado de harmonia pode ser quebrado pela tentativa de dominação de um sobre o outro, gerando o estado de guerra. $\mathrm{O}$ pacto ou o contrato surgiu da necessidade de manutenção da liberdade natural (vida, liberdade e bens). Para que haja um governo ou uma autoridade civil é necessário o consentimento dos cidadãos. Este governo tem a finalidade de garantir a liberdade de toda a defesa dos direitos naturais básicos. Diferente de Hobbes, que sustenta o Estado Absoluto, o Estado Civil em Locke deve ser limitado, e regulado pelos indivíduos que pactuam o contrato. A comunidade tem o direito de resistência caso interesse da maioria não esteja sendo expresso pelo governante (SANTANA; OLIVEIRA; MEIRA, 2013, p. 01, grifos nossos).
\end{abstract}

Todavia, para o filósofo suíço Jean-Jacques Rousseau (1712-1778) o povo deveria ser o soberano e não o governante. Este deveria ser um representante da soberania popular, pois ao manter sua soberania, o povo preservaria sua liberdade civil, seu direito a ser cidadão. Assim, o Estado seria “[...] o responsável por garantir as condições para que os indivíduos pleiteiem o direito a propriedade, a educação é tomada como instrumento para garantia da igualdade. Cabe ao Estado reduzir a desigualdade" (SANTANA; OLIVEIRA; MEIRA, 2013, p. 01). Em Rousseau notadamente se observa o uso do termo cidadania e garantia de condições. Construtos esses muito próximo às ideias acerca das políticas públicas.

$\mathrm{Na}$ prática, o que se observa no sistema capitalista, de acordo com compreensão do sociólogo e economista alemão Karl Marx (1818-1883) sobre o Estado, é que este é essencialmente classista, ou seja, é representante de uma classe e não da sociedade em sua totalidade. Pois, 
[...] o poder político do Estado representativo moderno nada mais é do que um comitê para administrar os negócios comuns de toda a classe burguesa. O Estado seria originário da necessidade de um grupo, ou classe social, manter seu domínio econômico a partir de um domínio político sobre outros grupos e classes. [...], toda classe que aspira à dominação [...], deve conquistar primeiro o poder político, para apresentar seu interesse como interesse geral, ao que está obrigada no primeiro momento. É por isso que as ideias dominantes de uma época, são as ideias dos grupos dominantes (BODART, 2016, p. 01).

Marx viveu, observou, estudou, pesquisou e escreveu sobre o período da primeira revolução industrial, da exploração do trabalhador, das exorbitantes cargas horárias de trabalho, baixíssimos salários e péssimas condições de trabalhos. Tempos de muitas lutas por igualdade, liberdade e fraternidade, período da pós Revolução Francesa. Ainda não havia menções às políticas públicas. Mas, ainda hoje o Estado é uma relação de dominação com uso de aparelhos de coerção como afirmou Marx. Como se não fosse suficiente, a globalização incluiu o papel das organizações multilaterais ${ }^{5}$ que fortaleceram e impuseram restrições ao poder outrora absoluto dos Estados Nacionais (FORJAZ, 2000, p. $42)$.

Como se pôde observar, até meados do século XIX, não se falava na terminologia "políticas públicas". Com o avanço das condições democráticas, passou-se a entender que "Políticas Públicas é tudo que o governo faz e deixa de fazer, com todos os impactos de suas ações e de suas omissões" (AZEVEDO, 2003, p. 38 apud OLIVEIRA, 2010, p. 02).

Segundo Souza, em seu artigo "Estado da arte da área de políticas públicas: conceitos e principais tipologias" (2003), as políticas públicas surgem nos EUA como uma área de estudos em uma disciplina acadêmica e nutre relação direta com a ciência política, pois tudo o que um governo faz ou deixa de fazer é passível de formulações científicas e de análises de pesquisadores e avaliações. Souza (2003) ressalta as contribuições clássicas dos pensamentos de vários fundadores da área de políticas públicas, dentre eles destaca Easton (1965), que colaborou para a área ao defini-la "como um sistema, ou seja, como uma relação entre formulação, resultados e o ambiente. Segundo Easton, as políticas públicas recebem inputs dos partidos, da mídia e dos grupos de interesse, que influenciam seus resultados e efeitos" (SOUZA, 2003, p. 04).

Souza (2003, p. 07) apoia-se nos estudos de Theodor Lowi $(1964 ; 1972)$ para tratar sobre a tipologia das políticas públicas, identificando quatro tipos, a saber:

\footnotetext{
${ }^{5}$ Organização das Nações Unidas e a Organização. Organização Mundial do Comércio. Fundo Monetário Internacional. Banco de Compensações Internacionais. OMC. ONU. UNESCO
}

Cadernos GPOSSHE On-line, Fortaleza, v. 4, n. Único, 2021. 
O primeiro é o das políticas distributivas, decisões tomadas pelo governo que desconsideram a questão dos recursos limitados, gerando impactos mais individuais do que universais, ao privilegiar certos grupos sociais ou regiões em detrimento do todo. $\mathbf{O}$ segundo é o das políticas regulatórias, que são mais visíveis ao público, envolvendo burocracia, políticos e grupos de interesse. O terceiro é o das políticas redistributivas, que atinge maior número de pessoas e impõe perdas concretas e no curto prazo para certos grupos sociais e ganhos incertos e futuro para outros; são, em geral, as políticas sociais universais, o sistema tributário e o sistema previdenciário e são as de mais difícil encaminhamento. $\mathbf{O}$ quarto é o das políticas constitutivas, que lidam com procedimentos. Cada uma dessas políticas públicas vai gerar pontos ou grupos de vetos e de apoios diferentes, processando-se, portanto, dentro do sistema político de forma também diferente (Grifos nossos).

As políticas públicas de Estado, sejam elas distributivas, regulatórias, redistributivas ou constitutivas, efetivam-se como permanentes ao serem normatizadas pela União, de modo que as políticas públicas de Estado são políticas públicas federais, que se materializam em planos, programas e projetos federais. Questiona-se, todavia, como as políticas públicas foram sendo desenvolvidas para a universalização das TDIC ante uma sociedade globalizada, que cada vez mais exige o uso de artefatos tecnológicos.

Sabe-se que "no Brasil, como na maior parte da América Latina, as políticas públicas de Tecnologias de Informação e Comunicação (TIC) concentram-se mais na inclusão social, diferentemente da Europa, por exemplo, onde são priorizados os setores de produção e negócios" (GUERRA; JORDÁN, 2010 apud ALVES et al, 2017, p. 19), ou seja, no âmbito nacional, as políticas públicas no que concernem às TDIC estão diretamente relacionadas à tentativa de minimizar as desigualdades de acesso às tecnologias. Ainda assim, enquanto alguns brasileiros utilizam smartfones de última geração, banda larga e um arcabouço moderno de artefatos tecnológicos, outros amargam a mais severa exclusão digital, alijados de qualquer recurso ou conhecimento sobre as TDIC. A exclusão digital, para além do acesso aos artefatos tecnológicos, também está associada à alfabetização para possibilitar ler e compreender o uso dos equipamentos (FREITAS; SOUSA; FIALHO, 2020).

Disponibilizar os meios de comunicação, educar os cidadãos e conscientizar as pessoas de como as tecnologias podem contribuir para suas tarefas e atividades, desde a facilidade ao acesso ao conhecimento e às novas oportunidades, deve ser uma política pública urgente no Brasil. Universalizar o conhecimento básico sobre o uso de computadores e demais aparelhos tecnológicos e da Internet é fundamental para minimizar o impacto negativo que eles podem trazer para os setores mais pobres. Atualmente, conhecimentos básicos de computação e Internet são crescentemente considerados pré- 
requisitos de acesso ao emprego e às políticas de universalização de acesso a esses saberes, que devem confrontar as complexidades associadas à apropriação efetiva das TDIC pelos setores mais pobres da população (ALMEIDA et al., 2005; SORJ; GUEDES, 2005).

Segundo Valente (2020), em uma pesquisa publicada pela Agência Brasil sob o título: "Brasil tem 134 milhões de usuários de internet", a maioria dos usuários acessa a internet pelo celular. Embora a quantidade de usuários e os serviços on-line tenham aumentado, ainda persistem diferenças de renda, gênero, raça e regiões aos artefatos digitais.

As informações são da pesquisa TIC Domicílios 2019 [...]. Conforme o estudo, $74 \%$ dos brasileiros acessaram a internet pelo menos uma vez nos últimos três meses. Outros $26 \%$ continuam desconectados. Se consideradas as pessoas que utilizam aplicativos que necessitam da conexão à internet (como Uber ou serviços de delivery de refeições), o percentual sobe para $79 \%$. Há 10 anos, $41 \%$ da população estava nesta condição. Deste então, o crescimento se deu em média de 3,3\% ao ano (s. p).

Para Gomes (2002), a exclusão digital vem acompanhada de problemas de ordem econômica, social, cultural, interesses políticos, entre outros. Segundo essa pesquisadora, incluem-se entre esses fatores a falta de uma infraestrutura de telecomunicação e o amplo processo de privatização dos meios de comunicação.

Atualmente, a exclusão digital no Brasil é desvelada por uma pandemia ${ }^{6}$, causada pela Covid $19^{7}$, que impôs o isolamento social e a necessidade mais acentuada da utilização dos artefatos digitais para possibilitar o bome office e as aulas remotas emergenciais. Esse acontecimento mundial, mostrou ao Brasil que é necessário desenvolver uma política pública séria, responsável e eficaz para minorar a exclusão digital e possibilitar maior igualdade e justiça social, também, no que concerne às condições de acesso às TDIC.

\section{CONSIDERAÇÕES FINAIS}

O ensaio desenvolvido objetivou discutir a interface entre a globalização e as TDIC, considerando a relevância de destacar a importância de políticas públicas para a sua universalização numa sociedade eminentemente capitalista. Observou-se que houve, a partir da Idade Moderna, grandes evoluções tecnológicas que facilitaram a globalização e as

6 Enfermidade epidêmica amplamente disseminada.

7 Os coronavírus (CoV) compõem uma grande família de vírus, conhecidos desde meados da década de 1960, que receberam esse nome devido às espículas na sua superfície, que lembram uma coroa (do inglês crown). Podem causar desde um resfriado comum até síndromes respiratórias graves, como a SARS. O Covid-19 é uma nova variante do coronavírus, até então não identificada em humanos. 
relações políticas, comerciais e sociais entre vários países do mundo. Todavia, essa globalização não gerou uma identidade planetária, ao contrário, cada país buscou competir e acumular capital sem ter-se tornado possível efetivar justiça social e maior igualdade de condições de vida entre os seres humanos.

O capitalismo foi-se ampliando de maneira desigual, e, enquanto alguns países foram dominando as tecnologias e ampliando seus lucros com o desenvolvimento e a venda de tecnologia de ponta, outros permanecem consumidores alijados de condições mínimas de competição no mercado. Essa desigualdade é perceptível no que concerne às TDIC, pois até em um mesmo país, como o Brasil, há àqueles que sequer possuem escolaridade básica para saber utilizar os artefatos, enquanto outros, nativos digitais, não apenas possuem renda para adquirir os produtos como dominam a tecnologia necessária.

Assim, verifica-se que a exclusão econômica é acentuada pela desigualdade tecnológica, o que dificulta o acesso ao conhecimento, fator que aumenta o abismo social entre ricos e pobres. Por esse motivo, faz-se urgente a elaboração de políticas públicas que invistam em educação e na igualdade de acesso às TDIC. Também é relevante pensar sistemas econômicos em que o foco seja a igualdade de condições de vida e não a competição e o lucro, desde o acúmulo do capital.

As desigualdades foram ressaltadas com a atual situação pandêmica iniciada no ano de 2020, que mostrou, com veemência, os prejuízos causados pelo isolamento social e pela impossibilidade dos mais pobres exercerem suas atividades laborais e educacionais mediada pelos artefatos tecnológicos, seja pelo desconhecimento acerca da sua utilização, seja pela impossibilidade de acesso. Importa, desse modo, ampliar discussões acadêmicas que discutam o imbricamento entre globalização, Estado, políticas públicas e exclusão digital com o mote de problematizar as desigualdades e, ao invés de normalizá-las, buscar incessantemente mecanismos de superação. 


\section{Referências}

ALMEIDA, et al. O retrato da exclusão digital na sociedade brasileira. Revista de Gestão da Tecnologia e Sistemas de Informação. v. 2, n. 1, 2005. Disponível em: https://www.scielo.br/j/jistm/a/7BZxyCX73JT9tJbBmsbfZ8w/abstract/?lang=pt. Acesso em: 10 abr. 2021.

ALVES et al. Avaliação de políticas públicas de TIC no Brasil: uma abordagem supradisciplinar. Perspectivas em Políticas Públicas, Belo Horizonte, v. X, n. 19, p. 19-55, jan./jun., 2017. Disponível em:

https://revista.uemg.br/index.php/revistappp/article/view/1798. Acesso em: 14 abr. 2021.

ALVES, Giovanni. As dimensões da globalização: Marx e a globalização como lógica do capital. Disponível em: https://www.ufff.br/pur/files/2011/04/Marx_e_a_Globalizacao.pdf, s/d. Acesso em: 09 abr. 2021

ARANHA, Maria Lucia de Arruda. História da Educação e da Pedagogia. 3 ed. São Paulo: Moderna, 2006.

BAUMAN, Zygmunt. A sociedade individualizada: vidas contadas e histórias vividas. Tradução. José Gradel. Rio de Janeiro: Zahar, 2008.

BAUMAN, Zygmunt. Modernidade liquida. Rio de Janeiro: Zahar, 2001

BITTAR, Marisa. História da educaşão: da antiguidade à época contemporânea. São Carlos: EdUFSCar, 2009.

BODART, Cristiano das Neves. O Estado para Karl Marx. Blog Café com Sociologia, mai. 2016.1. Disponível em: https://cafecomsociologia.com/wp-content/uploads/2020/11/OEstado-para-Karl-Marx.pdf. Acesso em: 13 abr. 2021

BREIER, Volmir Miki. A função do Estado em Hobbes. 2008. 71f. Dissertação (Mestrado em Filosofia) - Pontifícia Universidade Católica do Rio Grande do Sul, Porto Alegre, 2008. Disponível em: http://tede2.pucrs.br/tede2/handle/tede/2784. Acesso em: 12 abr. 2021.

BERSCH, Maria Elisabete; SCHLEMME, Eliane. Educação e tecnologias digitais: uma vivência pedagógica na formação de professores. Tear: Revista de Educação Ciência e Tecnologia, Canoas, v.6, n. 2, 2017. Disponível em:

https://periodicos.ifrs.edu.br/index.php/tear/article/view/2297. Acesso em: 20 abr. 2021.

CAMBI, Franco. História da Pedagogia. São Paulo: UNESP, 1999.

CHESNAIS, François. A globalização e o curso do capitalismo de fim-de-século. Revista Economia e Sociedade, Campinas, v.5, p.1-30, dez.,1995. Disponível em: https://www.eco.unicamp.br/ images/arquivos/artigos/430/01-CHESNAI5.pdf. Acesso em: 09 abr. 2021.

CORREIA, Rosângela Linhares; SANTOS, José Gonçalo dos. A Importância da Tecnologia da Informação e Comunicação (TIC) na Educação a Distância (EAD) do 
Ensino Superior (IES). Revista Aprendizagem em EAD, v. 2, nov., 2013. Disponível em: http://portalrevistas.ucb.br/index.php/raead. Acesso em: 11 abr. 2021. Acesso em: 14 abr. 2021.

DI FELICE, Massimo. Ser redes: o formismo digital dos movimentos net-ativistas. Revista Matrizes, n.7, p. 49- 71, jul./dez. 2013. Disponível em: https://www.revistas.usp.br/matrizes/article/view/69406. Acesso em: 10 abr. 2021.

FREITAS, Francisco Cláudio Costa de; SOUSA, Francisca Genifer Andrade de; FIALHO, Lia Machado Fiuza. Uso de tecnologias nas aulas de Geografia no ensino médio. EDUCA Revista Multidisciplinar em Educação, v. 7, p. 653-671, 2020. Disponível em: https://www.periodicos.unir.br/index.php/EDUCA/article/view/5064. Acesso em: 09 ago. 2021.

FORJAZ, Maria Cecília Spina. Globalização e crise do estado nacional. ERA, v. 40, n. 2, abr./jun., 2000.

GADOTII, Moacir. História das ideias pedagógicas. 8 ed. São Paulo: Cortez, 2006.

GOMES, Elizabeth. Exclusão digital: um problema tecnológico ou social? Instituto do Trabalho e Sociedade, ano 2, número especial, dez., 2002.

GONÇALVES, Gabriele. Processos de Produção. Disponível em: https://monografias.brasilescola .uol.com.br/sociologia/processos-producao.htm. Acesso em: 10 abr. 2021.

KENSKI, Vani Moreira. Educação e Tecnologias: o novo ritmo da informação. 2.ed. Campinas-SP: Papirus, 2007.

LÉVY, P. O que é virtual. 2 ed. São Paulo: Editora 34, 2011.

MORIN, Edgar; CIURANA, Emilio-Roger; MOTTA, Raúl D. Educar na era planetária. O pensamento complexo como método de aprendizagem pelo erro e incerteza humana. Tradução de Sandra T. Valenzuela. São Paulo: Cortez; Brasília DF: Unesco, 2003.

NASCIMENTO, Karla Angélica Silva do; FIALHO, Lia Machado Fiuza. Integração das Tecnologias Móveis em Aulas de Cursos Superiores da Área da Saúde. EAD em Foco, v. 10, p. 16, 2020. Disponível em:

https://eademfoco.cecierj.edu.br/index.php/Revista/article/view/989. Acesso em: 09 ago. 2021.

OLIVEIRA, Adão Francisco. Políticas públicas educacionais: conceito e contextualização numa perspectiva didática, 2010. Disponível em: https://www.sinprodf.org.br/wpcontent/uploads/2012/01/texto-4-pol\%C3\%8Dticas-p\%C3\%9Ablicas-educacionais.pdf. Acesso em: 14 abr. 2021.

OLIVEIRA, Carlos Alonso Barbosa de. Processo de industrialização: do capitalismo originário ao atrasado. São Paulo: Editora UNESP, 2003. Disponível em:

https://books.google.com.br/. Acesso em: 10 abr. 2021. 
SANTANA, Vagner Caminhas; OLIVEIRA, Daniel Coelho de; MEIRA, Thiago Augusto Veloso. Estado em Hobbes, John Locke e Rousseau, 2013. Disponível em:

https://www.efdeportes.com/efd186/estado-em-hobbes-locke-e-rousseau. Acesso em: 12 abr. 2021

SORJ, Bernardo; GUEDES, Luís Eduardo. Exclusão Digital: problemas conceituais, evidências empíricas e políticas públicas. Revista Novos Estudos. n. 72, jul., 2005. Disponível em: https://www.scielo.br/j/nec/a/vZ6fSRKr6SDKBHP6vdxbGTP/?lang=pt. Acesso em: 12 abr. 2021.

SOUZA, Celina. "Estado da Arte" da Área de Políticas Públicas: Conceitos e Principais Tipologias. Anais... XXVII Encontro Anual da Associação Nacional de Pós-Graduação e Pesquisa em Ciências Sociais (ANPOCS). GT: Políticas Públicas. Caxambu, MG. 21-25 de outubro de 2003.

STIGLITZ, Joseph E. A globalização e seus maleficios: a promessa não-cumprida de benefícios globais. Ed. Futura: São Paulo, 2002, 327 p.

VALENTE, Jonas. Brasil tem 134 milhões de usuários de internet. Agência Brasil. Brasília. 2020. Disponível em: https://agenciabrasil.ebc.com.br/geral/noticia/2020-05/brasil-tem134-milhoes-de-usuarios-de-internet-aponta-pesquisa. Acesso em: 13 abr. 2021.

WINTER, Lairton Moacir. A concepção de Estado e de poder político em Maquiavel. Tempo da Ciência, v.13, n. 25, p. 117-128, jan./jun., 2006. Disponível em: http://erevista.unioeste.br/index.php/tempodaciencia/article/viewFile/1532/1250. Acesso em: 12 abr. 2021.

Recebido em: 10/8/2021

Aceito em: 30/8/2021

Publicado online em: 2/9/2021 